\title{
An Assessment Of The Availability Of Extensive Reading Resources In Public Primary Schools In Owerri Municipal, Imo State, Nigeria
}

\author{
RICHARD C. IHEJIRIKA 1 (D) $\triangle$, UGOMMA A. AGWUOCHA ${ }^{2} \mathbf{8}$ (D) and CHIOMA N. IBE 9 (D) \\ ${ }^{123}$ Directorate Of General Studies, Federal University Of Technology, Owerri, Nigeria \\ $\triangle$ Corresponding Author: RICHARD C. IHEJIRIKA, E-mail: chinedumihejirika@gmail.com
}

\author{
ARTICLE INFORMATION \\ Received: May 11, 2021 \\ Accepted: June 17, 2021 \\ Volume: 3 \\ Issue: 6 \\ DOI: 10.32996/ijels.2021.3.6.3
}

\section{KEYWORDS}

Extensive reading, proficiency, reading culture, habit formation, second language

\section{ABSTRACT}

Research findings have consistently pointed to the fact that there is a correlation between extensive reading and proficiency in the target language, especially in a second language situation. Since reading is a process of habit formation, some linguistic scholars have argued that the primary school level is the most suitable for laying a strong foundation for the formation of extensive reading habits. Against this background, this study assessed the availability of extensive reading resources in public primary schools in Owerri Municipal, Imo State, Nigeria. The objective was to assess the availability of extensive reading resources in the public primary schools to determine whether the school environment is conducive enough to enhance extensive reading culture. The Behaviourist Theory of language learning guided the research and the research design was a survey method. Out of a total of twenty-seven primary schools in the Municipal, fifteen were randomly selected and investigated. With the instrument of a questionnaire, data were collected from heads of the schools. The data were analysed, using frequency count and simple percentages. From the analyses, it was revealed that virtually all the schools investigated lacked adequate extensive reading resources. Consequently, it is concluded that the non-availability of the extensive reading resources in the schools investigated may be partly responsible for the seeming poor extensive reading culture which is noticed among some contemporary students. It is, therefore, recommended that efforts should be made by the Imo State Government and, by extension, other state governments to ensure that primary schools in their states are equipped with the necessary extensive reading resources in order to encourage the pupils to cultivate an extensive reading culture in the target language.

\section{Introduction}

In a literate society, reading is one language skill that is critical in acquiring and learning a language, especially in a second language situation. As a result, it has continued to be an area of interest among linguistic scholars and researchers. Reading has been defined in diverse ways, pointing to the same idea and process. For instance, Pang (2003) states that reading is all about understanding written texts. According to the source, it is a complex activity involving both perceptions and thought and consists of two related processes: word recognition and comprehension. The source maintains that word recognition refers to the process of perceiving how written symbols correspond to one's spoken language, while comprehension is the process of making sense of words, sentences and connected text. The author adds that readers typically use background knowledge, vocabulary, grammatical knowledge, experience with text, and other strategies to help them understand written texts.

For the simple fact that reading is an exercise that is embarked upon for different purposes, two main types of reading can be distinguished: intensive reading and extensive reading. Distinguishing between the two reading types, Alo (1977) posit that:

While intensive reading is a detailed and careful reading of written materials

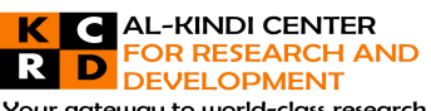

Your gateway to world-class research

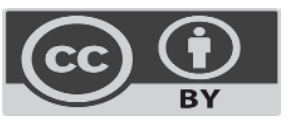

Published by Al-Kindi Center for Research and Development. Copyright (c) the author(s). This open access article is distributed under a Creative Commons Attribution (CC-BY) 4.0 license 
for the purpose of obtaining specific information in one's discipline or profession, extensive reading is the type we do usually during leisure to familiarize ourselves with a wide variety of reading matter such as newspapers, fiction, short stories, biography, autobiography and many others.

As the focus of this study, extensive reading (from now on ER) could also be said to refer to the kind of reading students do on their own with no help or guidance from the teacher. It is "an approach to the teaching and learning of second language reading in which learners read large quantities of books and other materials that are well within their linguistics competence" (Bamford \& Day, 1998, p. xiii). As an approach, teaching ER "is based on the belief that when students read for general comprehension of large quantities of texts of their own choosing, their ability to read will consequently improve" (Aebersold \& Field, 1997, p. 43).

According to Susser \& Robb (1990), "ER is reading (a) of large quantities of material or long text; (b) for global or general understanding (c) to obtain pleasure from text. Further, because (d) reading is individualised, with the students choosing the books they want to read, (e) the books are not discussed in class" (p. 157).

Lituanas, Jacobs, and Renenandya (1999) state that ER can be defined as reading large quantities of material for information or pleasure. According to the source, many names have been given to ER programmes, including Book Flood, Uninterrupted Sustained Silent Reading (USSR), Drop Everything and Read (DEAR), Silent Uninterrupted Reading for Form (SURF), and Extensive Reading and Information Literacy (ERIL).

With regard to the nature and characteristics of ER, Day and Bamford (1998, pp. 7-8) list the following:

(i) Students read as much as possible, perhaps in and definitely out of class.

(ii) A wide variety of materials on a wide range of topics is available so as to encourage reading for different reasons and in different ways.

(iii) Students select what they want to read and have the freedom to stop reading material that fails to interest them.

(iv) The purposes of reading are usually related to pleasure, information and general understanding. These purposes are determined by the nature of the material and the interests of the students.

(v) Reading in its own is rewarded. There are few or no follow-up exercises to be completed after reading.

(vi) Reading materials are well within the students' linguistic competence in terms of vocabulary and grammar. Dictionaries are rarely used while reading because the constant stopping to look up words makes fluent reading difficult.

(vii) Reading is individual and silent, at the students' own pace, and outside class, done when and where the student chooses.

(viii) Reading speed is usually faster rather than slower as students read books and other materials that they find easily understandable.

(ix) Teachers orient students to the goals of the programme, explain the methodology, keep tracks of what each student reads, and guide students in getting the most out of the programme.

(x) The teacher is a role model of a reader for students - an active member of the classroom reading community, demonstrating what it means to be a reader and the rewards for being a reader.

The specific benefits of extensive reading are manifold and wide-ranging. They have been cited by many scholars, researchers and teachers who have been deeply involved in this instructional approach for a very long time. From Nation (1997), Warring (2007), Day and Bamford (1998), and Prows (2003), the following benefits of ER are reported:

(i) ER builds automaticity of word recognition.

(ii) Automatic recognition of words allows lexical access - the automatic calling up from memory of a word's meanings and its phonological representation.

(iii) ER builds vocabulary knowledge.

(iv) Comprehension and fluent reading depend on automatic word recognition and vocabulary knowledge and thus are advanced through ER.

(v) Fluent reading allows the reader to move from word-by-word decoding to processing ideas, which is essential to higher-level reading and thinking skills.

(vi) ER builds awareness of grammatical structures and the ability to quickly and accurately process sentence structures.

(vii) ER promotes learner's background knowledge.

(viii) ER promotes learners' positive attitude toward reading. It fosters their confidence and motivation to read.

(ix) ER increases exposure to the target language. 
(x) ER reinforces a grasp of language that is taught in class. In addition, it provides students with an excellent opportunity to consolidate what they have learned, which is an essential aspect of foreign language learning.

(xi) Research studies also show that extensive reading improves learners' writing skills, listening and speaking skills and examination results.

From the foregoing benefits of ER, it is obvious that ER promotes reading culture and enhances proficiency in the target language. Against this backdrop, it has become absolutely necessary to institute ER culture, beginning from the primary school level, to catch them young towards cultivating the required ER habit, which will positively impact their academic pursuit later in their lives.

Another component of this investigation is availability ER resources in the school setting. ER resources are reading and nonreading materials that facilitate the implementation of ER curriculum. For the reading materials, they are written texts that are basically read for pleasure. Ahmad $(1997$, p. 85$)$ listed reading materials that are read for pleasure to include:

1. Literary works

i. short stories

ii. plays

iii. poems

2. Non-Literary works

i. daily newspapers, weekly or monthly magazines

ii. biographies and Autobiographies

iii. social commentaries

The non-reading materials in the context of this study include non-human and human resources which should be in place for implementation of ER curriculum. They include, for instance, functional library and library personnel to manage the library and any other measures that could be put in place to encourage the learners to cultivate the culture of reading and making effective use of the library. In this context, library personnel include a professional librarian and library attendants who have the capacity to manage the library so that it would achieve the objective for which it is set up. Other measures that could be put in place to enhance reading culture and effective use of the library include creating forums such as seminars and workshops where the pupils are periodically educated on the need for them to make effective use of the library and create time for ER. Related to the foregoing is creating catchy and motivating write-ups which emphasise and encourage ER in the form of posters displayed at strategic places for the pupils to read from time to time.

It is strongly hoped that if these ER resources are put in place in primary schools, it will go a long way in encouraging the pupils to lay a very strong foundation for ER, which would enable them to be proficient in the target language in the long run. Notice that the school, this time primary school, has a leading role to play in creating a conducive environment for the realisation of ER culture. The reason is that many pupils in public primary schools come from an illiterate and poor home background where parents may not appreciate the essence of ER and for such unfortunate pupils, the school becomes the ultimate last hope for the provision of the ER resources.

\subsection{Statement of the Problem}

In the Nigerian context in contemporary time, primary education which supposedly ought to be a basic education foundation upon which other levels of education should be built, has tremendously deteriorated to the extent that some graduates of primary school hardly write their name correctly, let alone construct a simple sentence in the target language, English, either in speech or writing. In fact, only very few pupils who pass through primary school, especially public primary school, could be said to be barely literate. It is in recognition of this fact that this study aims at assessing the availability of ER resources in public primary schools in Owerri Municipal since research findings have consistently pointed to the fact that there is an overwhelming significant correlation between ER and proficiency in the target language.

\subsection{Objective of the Study}

Specifically, the thrust of this investigation is to assess the availability of ER resources in public primary schools in Owerri Municipal, Nigeria in order to determine whether the environments of the schools are rich enough to promote ER culture.

\subsection{Research Questions}

This investigation aims at providing answers to the following questions:

i. $\quad$ Are ER resources available in public primary schools in Owerri Municipal, Nigeria?

ii. Is the number of ER resources available in public primary schools sufficient to instil in the pupils' ER culture? 


\subsection{Scope of the Study}

This research was carried out at Owerri Municipal Council, which incidentally is one of the twenty-seven local government councils that make up Imo State, Nigeria. It is an urban council located in Owerri City, the capital of Imo State. There are twentyseven public primary schools located in the Municipal Council and out of this number, fifteen schools were randomly selected and investigated.

\subsection{Theoretical Framework}

This study is guided by the Behaviourist Theory of language learning and acquisition. The Behaviourist Theory was influenced by "Behaviourism", a psychological theory founded by J.B. Watson in 1924. The main tenet of "Behaviourism" is that "everything which some refer to as mental activity, including language use, can be explained in terms of habits, or patterns of stimulus and response built up through conditioning" (Malinkjar \& Anderson, 1991, p.53).

Although Leonard Bloomfield is noted to be the first linguist to have a publication on behaviourist linguistics, following the publication of his book entitled Language in 1935, the most vigorous application of the behaviourist theory to the study of language is probably Verbal Behaviour published in 1957 by B.F. Skinner, one of the most famous behaviourist psychologists of the twentieth century. In this book, Skinner makes four basic claims about language learning, and the claims are:

i. language behaviour can be accounted for in a way that is in principle not different from the behaviour of rats in laboratory conditions,

ii. language behaviour can be explained in terms of observable events, without reference to the internal structure of the organism,

iii. this descriptive system is superior to others because its terms can be defined with reference to experimental operations, and

iv. it is able to deal with semantics in a scientific way (Malinkjar \& Anderson, 1991, p. 540).

When we relate the behaviourist tradition to language acquisition and learning, what it suggests is that language learning, especially non-native language is a process of imitation and reinforcement, that is, learners try to copy and imitate what they hear or read and by regular practice, they form a set of acceptable habits in the new language. Agreeing with this view while commenting on the theory, Crystal (1997) states that "language acquisition has long been thought of as a process of imitation and reinforcement. Children learn to speak, in the popular view, by copying the utterances heard around them" (p. 234).

Also supporting the view of behaviourist linguists, Brooks (1960) and Rivers (1964) see language behaviour as tantamount to a skill or a habit. Consequently, while Rivers (1974) is of the view that foreign-language learning is basically a mechanical process of habit formation, Brooks (1960) concurs that the single paramount fact about language learning is that it concerns, not problem-solving, but the formation and performance of habits. In the same vein, Wilkins (1992) draws an analogy between language learning and other skills when he says:

Learning a language is like learning to type, to ride a bicycle or to carry out any of the other routines that we characterize as habits. They are forms of human activity which, once learned, can be carried out without the conscious use of one's cognitive processes (p. 164).

Given the views expressed above, it is obvious that the Behaviourist Theory of language learning and acquisition is a suitable theoretical framework that guides the present investigation, which is all about assessing the availability of ER resources in public primary schools. It is hoped that if ER resources are made available in primary schools, the pupils are encouraged to make effective use of them. It would not only encourage them to cultivate the habit of reading extensively but would on the long run enhance their proficiency in both spoken and written English.

\section{Methodology}

\subsection{Research Design}

The research design used in this study is Survey Method. Out of twenty-seven (27) public primary schools in Owerri Municipal Council, fifteen (15) schools were randomly selected and investigated. The schools are listed in Table 1 below. 
Table 1: List of Primary Schools in Owerri Municipal Council Investigated

\begin{tabular}{|ll|}
\hline 1. & Housing Estate Primary School, Aladinma, Owerri \\
2. & Shell Camp Primary School, Owerri \\
3. & Model Shell Camp Primary School, Owerri \\
4. & Mann Street Primary School, Owerri \\
5. & Ikenegbu Layout Primary School, Owerri \\
6. & Uzii Layout Primary School, Owerri \\
7. & Uzii Layout Primary School II, Owerri \\
8. & Township Primary School, Owerri \\
9. & Urban Primary School, Owerri \\
10. & Waterside Primary School, Owerri \\
11. & Central School, Owerri \\
12. & Model Primary School, Owerri \\
13. & World Bank Primary School, Owerri \\
14. & Development Primary School I, Owerri \\
15. & Sam Njemanze Primary School I, Owerri \\
\hline
\end{tabular}

\subsection{Population}

The population of the study comprised fifteen (15) head teachers of the fifteen (15) public primary schools randomly selected in Owerri Municipal Council.

\subsection{Instrument for Data Collection}

The instrument for data collection was a questionnaire, which was administered to the fifteen (15) school heads of the public primary schools investigated. The questionnaire sought answers to questions on the availability of ER resources in the school.

\subsection{Method of Data Collection}

The researchers visited the fifteen primary schools and had one-on-one interactions with each school head. The questionnaire was given to each school head, who was requested to fill the questionnaire on the spot. All the school heads complied, which made it possible for the researchers to have $100 \%$ retrieval of the completed questionnaire.

\subsection{Method of Data Analysis}

Following the nature of the answers, the researchers got from the subjects based on the questions on the questionnaire, the data collected were analysed, using frequency count and simple percentages.

\section{Data Presentation and Analysis}

\section{1 Availability of Functional Library in the Public Primary Schools}

The responses of the respondents to the questionnaire administered to them on the availability of functional libraries in their schools were analysed. The results of the analysis as tabulated in Table 2 below, reveals that only three (3) of the fifteen (15) schools investigated had a library building while twelve (12) of the schools had classrooms converted to a library. The result of the analysis also shows that although the schools made provision for library activities on their time-tables and made it compulsory for the pupils, the libraries are not well equipped to meet the ER needs of the pupils. In the light of these revelations, it is, therefore, concluded that the public primary schools in Owerri Municipal, Imo State, Nigeria, do not have functional libraries, which are the bedrock for developing a meaningful ER culture among pupils in a school setting. 


\section{Table 2: Availability of Functional Library in the Primary Schools}

\begin{tabular}{|c|c|c|c|c|c|c|}
\hline & AG & $\%$ & DA & $\%$ & TOT & $\%$ \\
\hline 1. My school has a school library. & 15 & 100 & 0 & 0 & 15 & 100 \\
\hline 2. The library is a whole building set aside & & & & & & \\
\hline For library activities. & 3 & 20 & 12 & 80 & 15 & 100 \\
\hline 3. The library is a classroom, converted to & & & & & & \\
\hline To a library. & 12 & 80 & 3 & 20 & 15 & 100 \\
\hline 4. The librarian in my school is professional & & & & & & \\
\hline librarian. & 1 & 6.67 & 14 & 93.33 & 15 & 100 \\
\hline 5. In your school time-table is there provision & & & & & & \\
\hline for library activities for the pupils. & 15 & 100 & 0 & 0 & 15 & 100 \\
\hline 6. If there is provision for library activities is & & & & & & \\
\hline is it made compulsory for the pupils? & 15 & 100 & 0 & 0 & 15 & 100 \\
\hline $\begin{array}{l}\text { 7. My impression of my school library is that } \\
\text { it is equipped enough to meet the }\end{array}$ & & & & & & \\
\hline the ER needs of the pupils. & 2 & 13.33 & 13 & 86.67 & 15 & 100 \\
\hline
\end{tabular}

Legend: $A G=A G R E E, D A=$ DISAGREE, TOT $=$ TOTAL

\subsection{Availability of ER resources in Public Primary Schools}

The subjects' responses were analysed to determine the availability of ER resources in their school libraries. The analysis as shown on Table 3 below shows that about $80 \%$ of the schools investigated do not have in their libraries the core extensive reading materials such as novels, plays and poetry books. Similarly, $86.67 \%$ of the schools do not have magazines, biographies and autobiographies in their libraries. Also, $100 \%$ of the schools do not have local and national newspapers placed in their libraries on a daily basis. The analysis also revealed that none of the schools provided the encouragement and education of the pupils to cultivate the habit of reading extensively. Based on these revelations, it is concluded that the public primary schools in Owerri Municipal Council, Imo State, Nigeria are grossly lacking in ER resources.

\section{Table 3: Availability of ER Resources in Public Primary Schools}

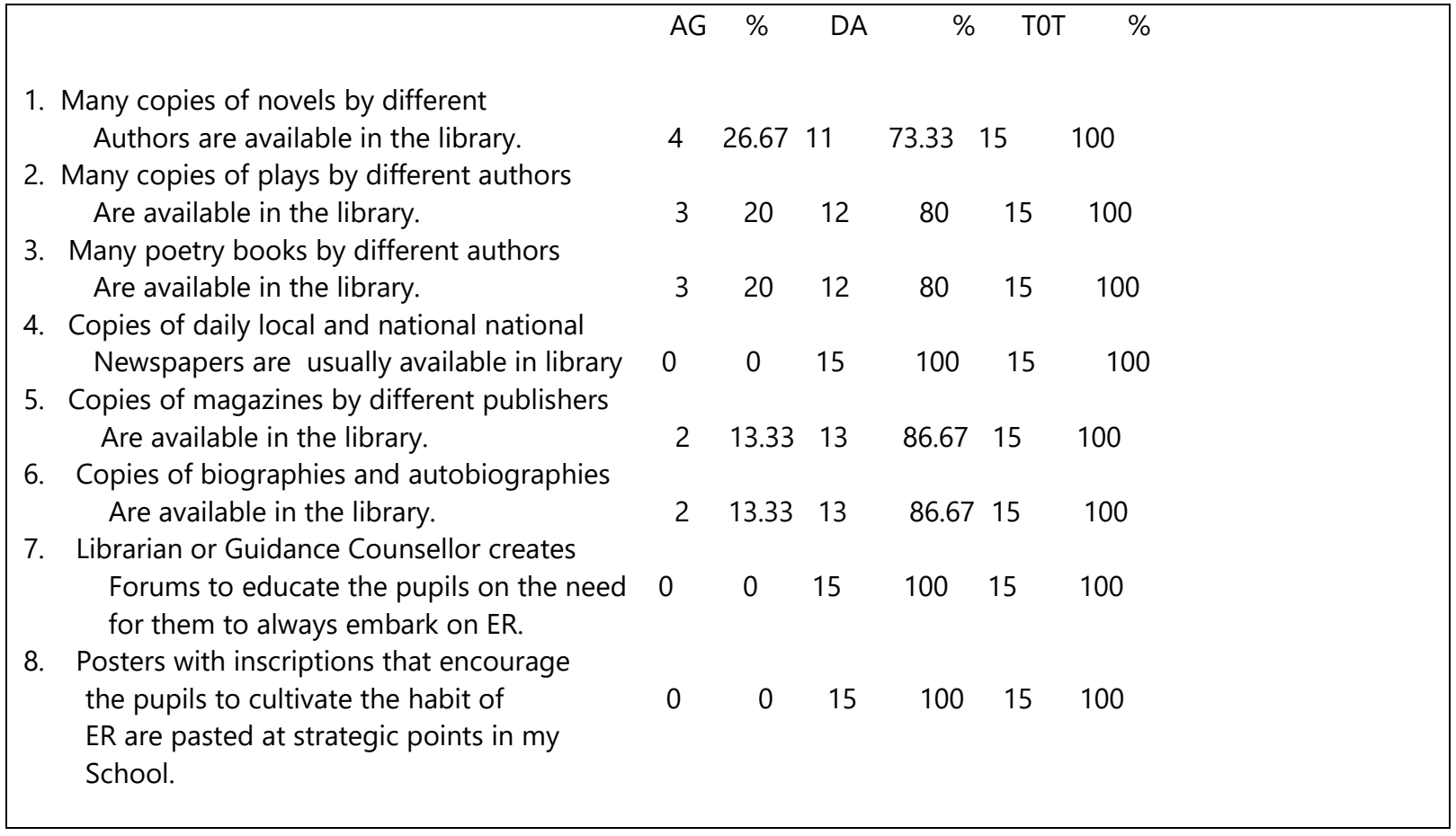

Legend: AG = AGREE, DA = DISAGREE, TOT $=$ TOTAL 


\section{Discussion}

The analysis of the data presented in Table 2 above shows that the public primary schools in Owerri Municipal, Imo State, Nigeria do not have functional libraries. This finding, from all indications, is not out of place. A visit to some public primary schools in Owerri Municipal, Imo State, Nigeria, will no doubt show that the infrastructures, including library, in most primary schools are in total decay. This ugly development is basically a result of misplacement of priority by successive government in the State. Experience has shown that the governments have consistently placed other frivolous interests above primary education. The foundation for effective reading ideally should be laid at the primary school level and one of the feasible ways to achieve this purpose is to ensure that functional libraries are built and equipped with the necessary library resources for the use of the pupils. The absence of functional libraries in primary schools, no doubt, is partly responsible for the seeming poor reading culture being noticed among pupils, which in effect retards their ability to be proficient in both spoken and written communications in English and even in their local languages. This is so because linguistic scholars have often reiterated that the best way to be proficient in a language is by reading materials written in that language (Krashen, 1984).

Another startling revelation from this study is the fact that reading materials such as novels, plays, poetry, newspapers, magazines, biographies, autobiographies and so on, which Ahmad, 1997 considers being materials to be read for pleasure and, by extension, part of ER resources, are either completely not available or grossly inadequate where they are available in the libraries of the schools investigated. For instance, in the analysis in Table 3 above, it is evident that 100\% of the schools investigated do not have daily newspapers in their library. On the other hand, $86.67 \%$ of the schools do not have magazines, biographies and autobiographies in their libraries. Also, no efforts are being made by the schools' authorities to encourage the pupils to develop the habit of reading extensively. This is an unfortunate development which has made public primary schools in the state a laughing stock. This is why many products of public primary schools hardly read or write efficiently. As a result, many parents are currently sceptical about registering their children in public primary schools. In fact, it is now a case of all roads lead to private primary schools. Even poor parents now work very hard to raise funds to take their children to private schools. This trend portends danger because public primary schools may go extinct for lack of patronage if the situation is not drastically changed. Secondly, those who may still insist on public primary schools for whatever reason may have their wards still wallowing in illiteracy even after graduating from school. In all, it would be a disaster for a nation (Nigeria) that prides itself as the giant of Africa to still have some of her citizens wallow in illiteracy even in this twenty-first century.

\section{Conclusion}

The thrust of this investigation is to assess the availability of ER resources such as functional libraries, reading materials such as novels, plays, poetry, daily newspapers, magazines, biographies, autobiographies and encouragement of pupils by the school management through open forums, seminars and placement of inscriptions on notice boards and at strategic places that encourage pupils to form the habit of reading extensively. In view of the study's findings as discussed above, it is concluded that the ER resources are either not available or where they are available they are grossly inadequate to meet ER needs of the pupils in public primary schools in Owerri Municipal Council of Imo State, Nigeria.

\section{Recommendations}

Against the backdrop of the findings, discussions and conclusion of this investigation, the following recommendations have become inevitable:

i The Imo State Government should give the primary school education in the State the pride of place it deserves by ensuring that adequate budgetary allocation is made annually for school education.

ii Government should ensure that functional library is established in every primary school in the State.

iii Professional librarians should be deployed to man the library in each primary School in the State.

iv The primary school libraries should be equipped with adequate ER materials such as novels, plays, poetry, newspapers, magazines, biographies, autobiographies and so on.

$v \quad$ The school management should create forums such as seminars, workshops and other ways of reaching out to the pupils to encourage them to form the habit of reading extensively.

vi An investigation such as this should be carried out in private primary schools Owerri Municipal Council in order to compare notes. 


\section{References}

[1] Aebersold, J.A. \& Field, M.L. (1997). From reader to reading teacher. Cambridge $2^{\text {nd }}$ ed. UK:

Cambridge University Press Ahmad, S.B. (1997). Recreational reading. In Helen Chukwuma and Emeka Otagburuagu (eds). English for Academic Purposes. Onitsha: Africana-Fep Publishers Ltd.

[2] Alo, M.A. (1997). Reading and vocabulary development. In Helen Chukwuma and Emeka Otagburuagu (Eds), English for academic purposes (pp 33-102). Onitsha: Africana-Fep

[3] Brooks, N. (1960). Language and language learning. New York: Harcourt, Brace and World.

[4] Crystal, D. (1987). The Cambridge encyclopaedia of language. Cambridge: Cambridge University Press.

[5] Day, R. \& Bamford, J. (1988). Extensive reading in the second language classroom. Oxford: Oxford University Press.

[6] Krashen, S.D. (1984). Writing: Research theory and practice. Oxford: Pensaman Press.

[7] Malmkjaer, K. \& Anderson, J.M. (Eds). (1991). The linguistics encyclopaedia. London: Routledge.

[8] Nation, P. (1997). The language learning benefits of extensive reading. The Language Teacher, 21 (5), 13-16.

[9] Pang, E.S. (2003). Teaching reading. Htt://www.curtin.edu.au/curtin/dept/smec/ine (Accessed July $1^{\text {st }}, 2010$ ).

[10] Prowse, J. (2003). Graded Readers. ELT Journal, 55(3), 300-324.

[11] Rivers, W.M. (1964). The psychologist and the foreign language teacher. Chicago: Chicago University Press.

[12] Sussar, B. \& Robb, T.N. (1990). (1990). EFL, extensive reading instruction: Research and procedure. JAL Journal, 12(2), 161-185.

[13] Warring, R. (2007). The language learning benefits of extensive reading. The Language Teacher, 21(5), 13-18.

[14] Wikins, D.A. (1992). Linguistics in language teaching. London: Edward Arnold (Publishers) Ltd. 